\title{
Avaliação reológica e físico-química da gelificação térmica do surimi de jundiá
}

\author{
Claudio Rafael Kuhn ${ }^{(1)}$, Lisiane Mendes Torres(2), Alexandre da Trindade Alfaro(3), \\ Carlos Prentice-Hernández ${ }^{(4)}$ e Germano Jorge Dorneles Soares ${ }^{(2)}$
}

\begin{abstract}
(1)Centro Federal de Educação Tecnológica de Pelotas, Área de Ensino de Química, Praça Vinte de Setembro, no 455, Centro, CEP 96015-360 Pelotas, RS. E-mail: claudiorafael_kuhn@yahoo.com.br (2)Universidade Federal de Pelotas, Faculdade de Agronomia Eliseu Maciel, Departamento de Ciência e Tecnologia Agroindustrial, Laboratório de Análises Bromatológicas e Bioquímicas, Caixa Postal 354, CEP 96010-900 Pelotas, RS. E-mail: lisianemt@yahoo.com.br, germojds@ufpel.tche.br (3)Universidade Tecnológica Federal do Paraná, Campus de Francisco Beltrão, Linha Santa Bárbara, s/no, CEP 85601-971 Francisco Beltrão, PR. E-mail: alexandrealfaro@yahoo.com.br (4)Universidade Federal de Rio Grande, Departamento de Química, Laboratório de Tecnologia de Alimentos, Caixa Postal 474, CEP 96201-900 Rio Grande, RS. E-mail: dqmprent@furg.br
\end{abstract}

Resumo - O objetivo deste trabalho foi avaliar as características reológicas e físico-químicas da gelificação térmica do surimi de jundiá (Rhamdia quelen). Utilizaram-se quatro tratamentos térmicos, três estágios duplos - pré-aquecimentos a $60^{\circ} \mathrm{C}$ durante 30,45 e 60 min, seguidos de aquecimento a $90^{\circ} \mathrm{C}$ por $15 \mathrm{~min}$, e um único aquecimento direto a $90^{\circ} \mathrm{C}$ por $15 \mathrm{~min}$ - e três formulações: duas com inibidores protéicos - soroalbumina bovina + alfa $_{2}$-macroglobulina e clara de ovo - e uma sem inibidores. Amostras com inibidores protéicos e aquecimento direto alcançaram melhor gelificação, pelo incremento no módulo de elasticidade e decréscimo no ângulo de fase. Os géis pré-aquecidos apresentaram grande oscilação dos parâmetros viscoelásticos, o que comprometeu a formação da rede protéica tridimensional, formada durante a gelificação térmica do surimi. A concentração de peptídeos solúveis não sofreu alteração significativa, mesmo durante os estágios duplos, o que indica a ausência de proteólise, além de mostrar a proteção pelos inibidores à matriz protéica.

Termos para indexação: Rhamdia quelen, inibidores proteícos, matriz protéica, peptídeos solúveis, propriedades viscoelásticas.

\section{Rheological and physicochemical evaluation of thermal gelling of surimi from silver catfish}

\begin{abstract}
The objective of this work was to evaluate the rheological and physicochemical properties of thermal gelling of surimi from silver catfish (Rhamdia quelen). Four heating treatments were used: one-step heating at $90^{\circ} \mathrm{C}$, for $15 \mathrm{~min}$, was compared with three two-step treatments with pre-heating at $60^{\circ} \mathrm{C}$ for 30,45 and $60 \mathrm{~min}$, followed by heating at $90^{\circ} \mathrm{C}$ for $15 \mathrm{~min}$. Each heat treatment was used on three formulations: two with protease inhibitors (bovine serum albumin + alpha $_{2}$-macroglobulin and egg white) and a formulation without inhibitors. Samples with inhibitors and one-step heating reached better gelling, by an increase in the storage modulus and a decrease in phase angle. Pre-heated gels had large variation in viscoelastic parameters which interfered with the establishment of the protein network during thermal gelling of surimi. The soluble peptides concentrations did not change significantly, even when two-step heating was carried out, which indicates absence of proteolysis, besides showing protein network protection by inhibitors.
\end{abstract}

Index terms: Rhamdia quelen, protease inhibitors, protein network, soluble peptides, viscoelastic properties.

\section{Introdução}

A gelificação protéica termo-induzida é uma das propriedades funcionais mais importantes e estudadas na ciência dos alimentos. A compreensão das interações protéicas nos alimentos, que ocorrem durante o seu processamento, possibilita à indústria manipular suas propriedades funcionais, com redução mínima na qualidade nutricional (Motoki \& Kumazawa, 2000).
O surimi é uma base protéica miofibrilar, obtida do pescado, com alta funcionalidade e valor nutricional. Agelificação térmica da proteína é uma etapa importante na manufatura de vários produtos análogos e derivados à base de surimi. A elevação da temperatura promove alterações que levam à formação de uma estrutura protéica tridimensional, que contribui não somente para a elasticidade da textura, mas também para outras propriedades funcionais importantes para simular a 
aparência e textura da carne (Visessanguan et al., 2000; Gerrard, 2002; Totosaus et al., 2002).

As interações entre as regiões hidrofóbicas, situadas próximas à cabeça da molécula de miosina, têm início ao redor dos $50^{\circ} \mathrm{C}$. Entretanto, entre 50 e $70^{\circ} \mathrm{C}$, pode ocorrer a quebra da rede protéica ("modori") pré-formada, que é associada tanto a proteinases endógenas termicamente ativadas como à suscetibilidade térmica da proteína miofibrilar. Entre 80 e $90^{\circ} \mathrm{C}$, ocorre a formação de um gel opaco e forte, denominado "kamaboko", e a actomiosina, induzida por efeito do calor, passa a expor grupos reativos, que favorecem as interações hidrófobas proteína-proteína. A exposição de grupos sulfidrílicos internos e a formação de ligações dissulfeto conduzem à formação de géis termicamente irreversíveis, que aprisionam moléculas de água, por meio de ligações cruzadas (pontes dissulfeto, SS), consideradas vitais para a manutenção da estrutura. Essas ligações também podem controlar o grau de flexibilidade da cadeia polipeptídica, inclusive in vivo (Visessanguan \& An, 2000; Hamsakutty, 2003).

Essas interações intra e intermoleculares são consideradas essenciais na gelificação termo-induzida para os produtos à base de surimi. Entretanto, a capacidade da proteína miofibrilar para a gelificação está altamente relacionada a fatores como: a espécie utilizada; a conformação nativa da proteína, com variações dentro de uma mesma espécie de pescado; e condições de captura, conservação e processamento, para a obtenção de surimi (Visessanguan et al., 2000).

O jundiá (Rhamdia quelen) é uma espécie nativa de água-doce, abundantemente distribuída na América do Sul. Apesar de seu elevado potencial para aproveitamento na aqüicultura (rusticidade, boas taxas de reprodução, bom rendimento no processamento de surimi), trata-se ainda de uma espécie subutilizada para a obtenção de derivados de pescado. O estudo e a compreensão da gelificação protéica do surimi, em novas espécies, são importantes para: o melhor conhecimento da formação do gel e de sua textura; no conhecimento do potencial de utilização de espécies nativas, para oferecer alternativas na exploração e proteção dos recursos pesqueiros; para agregar valor ao pescado, atualmente com baixo valor comercial, e para potencializar a aqüicultura (Kuhn, 2006).

O objetivo deste trabalho foi avaliar as características reológicas e físico-químicas da gelificação térmica do surimi de jundiá.

\section{Material e Métodos}

Carcaças de jundiá criado em cativeiro foram obtidas no Departamento de Zootecnia, da UniversidadeFederal de Pelotas. O processamento inicial teve como etapas: a lavagem, evisceração, descabeçamento e lavagem final (em até 6 horas pós-captura), embalagem a vácuo e estocagem sob congelamento $\left(-30^{\circ} \mathrm{C}\right.$, por 30 dias); constituiu a matéria-prima para o processamento de surimi (Kuhn et al., 2007). O experimento foi realizado em 2005.

Na obtenção da polpa e processamento do surimi, o pescado previamente descongelado foi submetido ao processo de separação mecânica (Baader mod. 694, em cilindro com perfurações de $5 \mathrm{~mm}$ de diâmetro, Indústria Pesqueira Furtado S.A.). O processamento da polpa, no Laboratório de Tecnologia de Alimentos, da Universidade Federal de Rio Grande, teve como etapas a realização de duas lavagens, em tanques de polietileno $\left(\mathrm{t}<10^{\circ} \mathrm{C}\right.$, proporção $3: 1$ água/polpa), sob leve agitação ( $5 \mathrm{~min}$ ) e drenagem entre as lavagens (Lin \& Park, 1996; Kuhn, 2006; Kuhn et al., 2007). Após as lavagens, realizou-se o refino da polpa, por compressão (sistema pistão por cilindro, em aço inox com cilindro com perfurações de $2 \mathrm{~mm}$ de diâmetro), e a operação de drenagem final por centrifugação (Hidroextrator YL 15, Ankofood Machine Co Ltd.), tendo-se retirado o excesso de água da polpa (umidade máxima entre 70 e $75 \%$ ). Os crioprotetores - sorbitol $4 \%(\mathrm{p} / \mathrm{p})$ e tripolifosfato de sódio $0,3 \%$ $(\mathrm{p} / \mathrm{p})$ - foram misturados à polpa, e a pasta obtida foi dividida em três partes, para incorporação dos inibidores protéicos. À primeira parte, foi adicionada uma mistura de BSA (soroalbumina bovina) e alfa $_{2}$-macroglobulina (1 e $0,1 \% \mathrm{p} / \mathrm{p}$, respectivamente); à segunda parte, adicionou-se clara de ovo $3 \%(\mathrm{p} / \mathrm{p})$; e a terceira parte, sem inibidores protéicos, constituiu o controle. $\mathrm{O}$ produto foi congelado rapidamente e estocado $\left(-30^{\circ} \mathrm{C}\right.$, durante 30 dias $)$, para, assim, formar o surimi utilizado para a preparação do gel (Kuhn et al., 2007).

Na preparação do gel termoestável ("kamaboko"), amostras de surimi (200 g) foram descongeladas, tendo-se adicionado $\mathrm{NaCl}(3 \%)$ e fécula de mandioca (5\%); a mistura foi realizada em "cutter" (Metvisa, mod Cut-3), para a obtenção de uma pasta homogênea, durante $2 \mathrm{~min}$. A pasta foi acondicionada em envoltórios de colágeno (20 $\mathrm{mm}$ de diâmetro) e submetida a diferentes tratamentos térmicos 
(Kuhn, 2006): aquecimento direto - as amostras foram submetidas a uma única etapa de aquecimento a $90^{\circ} \mathrm{C}$, durante $15 \mathrm{~min}$ e, após o tempo de aquecimento, as amostras foram resfriadas em água gelada, durante 30 min, e mantidas sob refrigeração a $5^{\circ} \mathrm{C}$ (máximo de 24 horas), para as determinações físico-químicas; pré-aquecimento - as amostras foram incubadas à temperatura de $60^{\circ} \mathrm{C}$, durante três diferentes tempos 30, 45 e $60 \mathrm{~min}$ - e, em seguida, foram submetidas ao aquecimento a $90^{\circ} \mathrm{C}$, por $15 \mathrm{~min}$, para a formação definitiva do gel, e logo após, resfriadas em água gelada por 30 min, mantidas sob refrigeração a $5^{\circ} \mathrm{C}$ (máximo de 24 horas), para as determinações físico-químicas.

$\mathrm{Na}$ determinação da concentração de peptídeos solúveis, amostras do gel "kamaboko" (3 g) foram homogeneizadas com $27 \mathrm{~mL}$ de ácido tricloroacético $\operatorname{TCA}(5 \%, \mathrm{p} / \mathrm{v})$, incubadas $\left(4^{\circ} \mathrm{C}, 1\right.$ hora $)$ e centrifugadas (5.000 $\mathrm{g}, 5 \mathrm{~min})$. As proteínas recuperadas do sobrenadante foram quantificadas e expressas em $\mu \mathrm{mol}$ tirosina $\mathrm{g}^{-1}$ por músculo (Benjakul et al., 2004).

Para a análise das propriedades reológicas, amostras de surimi (8 g) - previamente preparadas para a obtenção do gel "kamaboko" - foram homogeneizadas em solução de $\mathrm{NaCl}$ 0,6 M à razão 1:1 (p/p) (Lee et al., 1997; Yongsawatdigul et al., 2000). A pasta obtida foi utilizada para a avaliação dos parâmetros de módulo de elasticidade (G') e ângulo de fase (AF), com o reômetro Haake Rheostress RS-150 (EKO Instruments Trading Co. Ltd.), pelo programa Rheowin Job Manager (Laboratório de Biopolímeros, Universidade Federal de Pelotas). As determinações foram conduzidas, tendose configurado o equipamento para ensaio no modo oscilatório, em placas paralelas de $20 \mathrm{~mm}$ de diâmetro, fenda de $1 \mathrm{~mm}$ (gap), freqüência de $2,1 \mathrm{~Hz}$, tensão de $0,05 \mu \mathrm{N} \mathrm{m}^{-2}$, e taxa de aquecimento de $2^{\circ} \mathrm{C}$ por min. As amostras (pastas de surimi) foram submetidas ao aquecimento contínuo de 10 a $90^{\circ} \mathrm{C}$ (aquecimento direto) e de 10 a $60^{\circ} \mathrm{C}$, tendo-se mantido esta última temperatura por até 1 hora (Benjakul et al., 2001; Alfaro, 2004).

$\mathrm{O}$ experimento foi conduzido em delineamento inteiramente ao acaso, em esquema fatorial $4 \times 3$ (quatro tratamentos térmicos e três formulações), com três repetições, no total de 36 amostras. Os dados foram submetidos à análise de variância (ANOVA), e as médias foram comparadas pelo teste de Tukey, a 5\% de probabilidade, pelo programa Statistica for Windows, versão 6.0 (Statsoft, 1998).

\section{Resultados e Discussão}

Sob aquecimento direto, amostras sem inibidores protéicos (controle) apresentaram incremento no módulo de elasticidade (G'), a partir dos $15 \mathrm{~min}$ de aquecimento a $38^{\circ} \mathrm{C}$, com acentuadas oscilações até o final desse período (Figura 1). As amostras com os inibidores protéicos apresentaram comportamento viscoelástico distinto do controle (sem inibidores protéicos), com menor oscilação dos parâmetros reológicos $\left(\mathrm{G}^{\prime}\right.$ e $\left.\mathrm{AF}\right)$ que, aliados ao incremento do G' e à pequena diminuição no $\mathrm{AF}$, durante o período de aquecimento, comprovaram a contribuição dos inibidores protéicos para a maior estabilidade da matriz protéica, durante a gelificação térmica.

$\mathrm{O}$ AF tem a vantagem de incorporar o efeito da contribuição do módulo de viscosidade (G”), pela razão G'/G'. Assim, a formação da rede protéica é caracterizada pelo predomínio da fase elástica (aumento em G') sobre a viscosa, que se reflete no decréscimo do $\mathrm{AF}$, com as alterações associadas à formação da estrutura e elasticidade, durante o processo de gelificação térmica (Visessanguan et al., 2000).

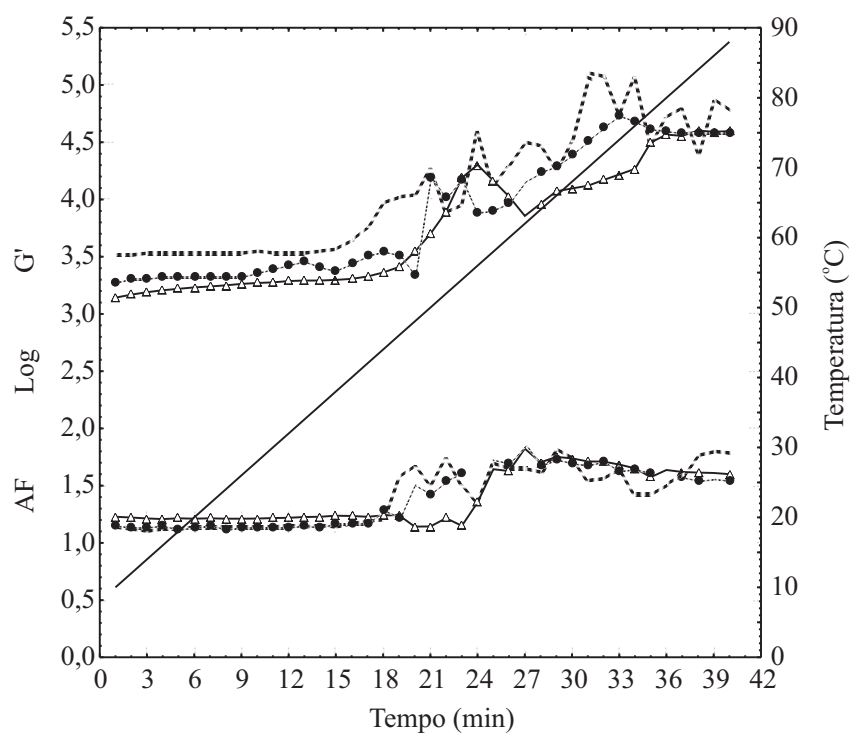

$\cdots \cdot \mathrm{C} \quad \square$ BPP $\quad \ldots . \cdots \mathrm{EW} \quad-\mathrm{T}\left({ }^{\circ} \mathrm{C}\right)$

Figura 1. Comportamento reológico de géis de surimi de jundiá (Rhamdia quelen), aquecidos a $90^{\circ} \mathrm{C}$ (etapa única de aquecimento). Propriedades viscoelásticas: G', módulo de elasticidade; AF, ângulo de fase. Géis: C, controle (sem inibidores protéicos); EW, clara de ovo; BPP, combinação de soroalbumina bovina (BSA) e alfa ${ }_{2}$-macroglobulina; $\mathrm{T}$ : temperatura $\left({ }^{\circ} \mathrm{C}\right)$. 
A característica de gelificação térmica do surimi de jundiá esteve em conformidade com os perfis de géis de surimi de escamudo-do-alasca (Theragra chalcogramma) e de alabote-dente-curvo (Atheresthes stomias), em que as modificações ocorreram a partir de $30^{\circ} \mathrm{C}$ (Yoo \& Lee, 1994; Visessanguan et al., 2000). Contudo, diferentes temperaturas foram constatadas no início da transição sol-gel, em géis de surimi de baga-de-lagoa (Nemipterus bleekeri) $-40^{\circ} \mathrm{C}-\mathrm{e}$ no músculo de vieira (Patinopecten yessoensis) $-22^{\circ} \mathrm{C}$ (Yongsawatdigul \& Park, 2003).

As oscilações observadas nos parâmetros viscoelásticos dos géis de surimi de jundiá (após 27 min de aquecimento, a $65^{\circ} \mathrm{C}$ ) podem ser ocasionadas pelo desdobramento da molécula de miosina, que produz aumento na fluidez do semigel que pode separar algumas redes protéicas já formadas. O processo caracteriza uma desnaturação, com a exposição de grupamentos sulfidrílicos ( $\mathrm{SH}$ ) subseqüentemente envolvidos na formação de ligações intermoleculares, no processo de agregação, que forma pontes dissulfeto, em temperaturas superiores a $60^{\circ} \mathrm{C}$ (Visessanguan et al., 2000).

Este comportamento também foi relatado sobre géis de surimi de polaca-do-alasca (Theragra chalcogramma) sem, no entanto, verificar-se nos géis de carpa-comum (Cyprinus carpio). As diferenças entre as espécies são atribuídas às características da molécula de miosina como sua conformação nativa, facilidade de interação, tamanho e comprimento da molécula que, por sua vez, são influenciadas por fatores inerentes ao espécime e ao habitat. Assim, alterações nas propriedades do gel ocorrem em razão de alterações no seu mecanismo de formação (Morrissey et al., 1993; Yongsawatdigul et al., 2000; Kuhn \& Soares, 2002).

Quando submetidos ao aquecimento prévio a $60^{\circ} \mathrm{C}$, os géis de surimi de jundiá apresentaram visíveis alterações nos perfis viscoelásticos, e mostraram, assim, o efeito da temperatura sobre a gelificação térmica (Figura 2). Esse efeito também foi observado em géis de alabote-dente-curvo, nos quais o módulo de elasticidade ( $\left.G^{\prime}\right)$, nas amostras sem inibidores protéicos, apresentou magnitude inferior ao gel de jundiá, com ângulo de fase constante ao longo do tempo (Visessanguan \& An, 2000).

As alterações verificadas nas propriedades reológicas dos tratamentos com pré-aquecimentos confirmam os resultados texturais em estudos prévios, em que os géis de surimi de jundiá atingiram menor força de compressão, em relação ao aquecimento direto a $90^{\circ} \mathrm{C}$ e em que, nas mesmas condições, os tratamentos com inibidores protéicos foram melhores que o controle (Kuhn et al., 2007).

A temperatura constitui a força motriz tanto para a gelificação, como para a desnaturação protéica, de origem proteolítica ("modori”) ou térmica. O perfil viscoelástico, observado no aquecimento direto $\left(90^{\circ} \mathrm{C}\right.$, $15 \mathrm{~min}$ ), evidenciou efeito térmico inibitório, sobre uma possível desnaturação ou proteólise, e o conseqüente favorecimento da gelificação protéica miofibrilar em altas temperaturas.

Efeito similar foi observado em espécies como tilápia (Oreochromis sp.), alabote-dente-curvo, e merluza (Merluccius sp.) (An et al., 1996; Yongsawatdigul et al., 2000; Visessanguan et al., 2001). No entanto, géis de carapau-do-japão (Trachurus japonicus) apresentaram proteólise e perda da capacidade de gelificação, pelo decréscimo de textura com o prolongamento do tempo de cocção a $70^{\circ} \mathrm{C}$ e, nas amostras controle, a força

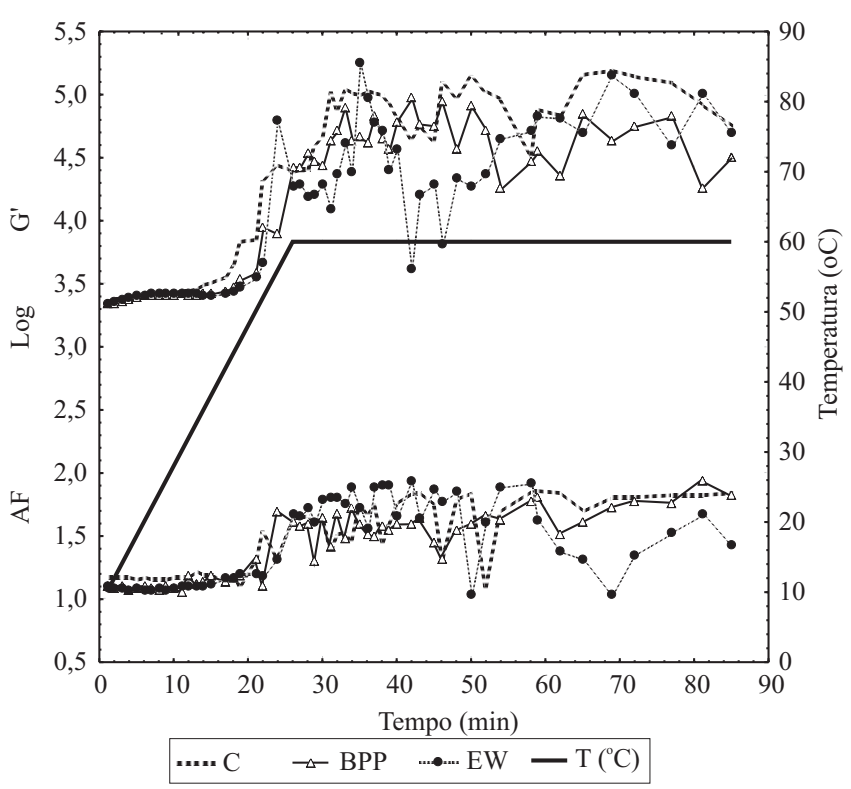

Figura 2. Comportamento reológico de géis de surimi de jundiá (Rhamdia quelen), pré-aquecidos a $60^{\circ} \mathrm{C}$ (duplo estágio de aquecimento). Propriedades viscoelásticas: G', módulo de elasticidade; AF, ângulo de fase. Géis: $\mathrm{C}$, controle (sem inibidores protéicos); EW, clara de ovo; BPP, combinação de soroalbumina bovina (BSA) e alfa ${ }_{2}$ macroglobulina; T: temperatura $\left({ }^{\circ} \mathrm{C}\right)$. 
de gel foi mensurável somente após 30 minutos de aquecimento (Chen, 2000).

A termoestabilidade da proteína de pescado e a quantidade de grupamentos sulfidrílicos parecem ser fundamentais para a gelificação térmica, fator inerente à espécie utilizada. O decréscimo de $\mathrm{SH}$ que se oxidam na formação de pontes dissulfeto SS, ocorreu com maior intensidade para a formação do gel termoestável, em amostras submetidas ao aquecimento direto sob altas temperaturas, favorecida pela presença de inibidores protéicos e verificada, anteriormente, em ensaios instrumentais de textura (Kuhn et al., 2007).

$\mathrm{O}$ efeito da formulação e dos sistemas de aquecimento sobre os géis pôde ser observado pelas concentrações de peptídeos solúveis (Tabela 1). Os valores encontrados foram similares aos relatados sobre a baga-da-lagoa e corvina-olhuda (Pennahia macrophthalmus), citados como fatores dependentes da espécie e condições de habitat, com influência nas propriedades de gelificação e textura (Morales et al., 2001; Benjakul et al., 2003).

As amostras cominibidores protéicos apresentaram menor quantidade de peptídeos solúveis, em relação ao controle (sem inibidores protéicos), o que comprova a influência desses compostos para a manutenção da integridade da matriz protéica. Em géis de surimi de pescada (Macrodon ancylodon), merluza-do-atlântico (Merluccius spp.) e corvina (Umbrina canosai), o uso dos mesmos inibidores também resultou na preservação da rede protéica, comprovada por ensaios instrumentais pela avaliação da coesividade, em condições similares de aquecimento (Kuhn et al., 2003; Murphy et al., 2005; Lempek et al., 2007).

Tabela 1. Concentração de peptídeos solúveis ( $\mu$ mol tirosina $\mathrm{g}^{-1}$ por músculo) de géis de surimi de jundiá (Rhamdia quelen), em diferentes formulações e tratamentos térmicos ${ }^{(1)}$.

\begin{tabular}{lclc}
\hline Formulação & $\begin{array}{c}\text { Concentração de } \\
\text { peptídeos solúveis }\end{array}$ & \multicolumn{1}{c}{$\begin{array}{c}\text { Tratamento } \\
\text { térmico }\end{array}$} & $\begin{array}{c}\text { Concentração de } \\
\text { peptídeos solúveis }\end{array}$ \\
\hline $\begin{array}{l}\text { Sem inibidores } \\
\text { protéicos }\end{array}$ & $3,44 \mathrm{a}$ & $60^{\circ} \mathrm{C}, 30 \mathrm{~min}+90^{\circ} \mathrm{C}$, & $3,07 \mathrm{a}$ \\
Clara de ovo & $2,70 \mathrm{~b}$ & $\begin{array}{l}15 \mathrm{~min} \\
60^{\circ} \mathrm{C}, 45 \mathrm{~min}+90^{\circ} \mathrm{C},\end{array}$ & $2,94 \mathrm{a}$ \\
& $2,21 \mathrm{c}$ & $\begin{array}{l}15 \mathrm{~min} \\
60^{\circ} \mathrm{C}, 60 \mathrm{~min}+90^{\circ} \mathrm{C},\end{array}$ & $2,88 \mathrm{a}$ \\
$\begin{array}{l}\text { Soro albumina } \\
\text { bovina e alfa } 2^{-}\end{array}$ & & $15 \mathrm{~min}$ & \\
macroglobulina & & $90^{\circ} \mathrm{C}, 15 \mathrm{~min}, \mathrm{sem}$ & $3,04 \mathrm{a}$ \\
& & inibidores protéicos & \\
\hline
\end{tabular}

$\overline{{ }^{(1)} \text { Médias seguidas de letras iguais, na coluna, não diferem entre si pelo teste }}$ de Tukey, a $5 \%$ de probabilidade.
Os diferentes sistemas de aquecimento (direto e duplos estágios), utilizados no experimento, não influenciaram as concentrações de peptídeos solúveis $(\mathrm{p}<0,05)$, o que caracteriza a ausência de atividade proteolítica, nos géis de surimi de jundiá. $\mathrm{O}$ prolongamento do tempo de pré-aquecimento, nas amostras submetidas ao duplo estágio a $60^{\circ} \mathrm{C}$, induziu o colapso da estrutura e a alteração nas propriedades reológicas, provavelmente pela excessiva interação intermolecular das cadeias protéicas e pela desnaturação térmica, o que caracteriza, um "modori" não proteolítico (An et al., 1996).

\section{Conclusões}

1. A gelificação térmica direta $\left(90^{\circ} \mathrm{C}\right.$, durante $\left.15 \mathrm{~min}\right)$ do surimi de jundiá (Rhamdia quelen) apresenta o melhor perfil viscoelástico.

2. Os inibidores protéicos promovem maior estabilidade da matriz protéica, durante a gelificação térmica direta $\left(90^{\circ} \mathrm{C}\right.$, durante $\left.15 \mathrm{~min}\right)$ do surimi de jundiá.

3. Independentemente dos tratamentos térmicos, os inibidores protéicos promovem maior proteção da matriz protéica, pela menor concentração de peptídeos solúveis.

\section{Agradecimentos}

À Coordenação de Aperfeiçoamento de Pessoal de Nível Superior e ao Conselho Nacional de Desenvolvimento Científico e Tecnológico, por bolsa concedida e suporte financeiro, respectivamente; à Universidade Federal de Pelotas, Departamento de Zootecnia, pelo fornecimento de matériaprima; à Universidade Federal de Rio Grande, pela disponibilização de instalações e equipamentos para o processamento de surimi e obtenção dos géis termoestáveis; à Universidade Federal de Pelotas, Laboratório de Biopolímeros, pela disponibilização do equipamento para os ensaios reológicos e ao Departamento de Ciência e Tecnologia Agroindustrial, por viabilizar a pesquisa.

\section{Referências}

ALFARO, A.T. Otimização do processo e determinação das propriedades funcionais da gelatina de ossos de pescado. 2004. 105p. Dissertação (Mestrado) - Universidade Federal de Rio Grande, Rio Grande.

AN, H.; PETERS, M.Y.; SEYMOUR, T.A. Roles of endogenous enzymes in surimi gelation. Trends in Food Science and Technology, v.7, p.321-326, 1996. 
BENJAKUL, S.; VISESSANGUAN, W.; CHANTARASUWAN, C. Effect of high-temperature setting on gelling characteristic of surimi from some tropical fish. International Journal of Food Science and Technology, v.39, p.671-680, 2004.

BENJAKUL, S.; VISESSANGUAN, W.; CHANTARASUWAN, C. Effect of medium temperature setting on gelling characteristics of surimi from some tropical fish. Food Chemistry, v.82, p.567-574, 2003.

BENJAKUL, S.; VISESSANGUAN, W.; ISHIZAKI, S.; TANAKA, M. Differences in gelation characteristics of natural actomyosin from two species of bigeye snapper, Priacanthus tayenus and Priacanthus macracanthus. Journal of Food Science, v.66, p.1311-1318, 2001.

CHEN, H.H. Effect of non-muscle protein on the thermogelation of horse mackerel surimi and the resultant cooking tolerance of kamaboko. Fisheries Science, v.66, p.783-788, 2000.

GERRARD, J.A. Protein-protein crosslinking in food: methods, consequences, applications. Trends in Food Science and Technology, v.13, p.391-399, 2002.

HAMSAKUTTY, H. Cysteine-free radical and radiation biology. Bulletin of the University of Iowa, v.1, p.1-10, 2003.

KUHN, C.R. Gelificação termo-induzida do surimi de jundiá (Rhamdia quelen) com uso de inibidores de protease. 2006. 95p. Tese (Doutorado) - Universidade Federal de Pelotas, Pelotas.

KUHN, C.R.; FILGUERAS, R.S.; TORRES, L.; VENDRUSCOLO, J.L.S.; SOARES, G.J.D. Caracterização textural e físico-química do gel de surimi de jundiá (Rhamdia quelen). Boletim do Centro de Pesquisa e Processamento de Alimentos, v.25, p.305-314, 2007.

KUHN, C.R.; SOARES, G.J.D. Proteases e inibidores no processamento de surimi. Revista Brasileira de Agrociência, v.8, p.5-11, 2002.

KUHN, C.R.;SOARES, G.J.D.;PRENTICE,C.;VENDRUSCOLO, J.L. Avaliação da força de gel de surimi de resíduos de pescadafoguete (Macrodon ancylodon) enriquecido com aditivos protéicos. Boletim do Centro de Pesquisa e Processamento de Alimentos, v.21, p.239-248, 2003

LEE, H.G.; LANIER, T.C.; HAMANN, D.D. Covalent cross-linking effects on thermo-rheological profiles of fish protein gels. Journal of Food Science, v.62, p.25-28, 1997.

LEMPEK, T.S.; MARTINS, V.G.; PRENTICE, C. Rheology of surimi-based products from fatty fish underutilized by the industry: Argentine croaker (Umbrina canosai). Journal of Aquatic Food Product Technology, v.16, p.27-44, 2007.
LIN, T.M.; PARK, J.W. Extraction of proteins from Pacific whiting mince at various washing conditions. Journal of Food Science, v.61, p.432-438, 1996.

MORALES, O.G.; RAMÍREZ, J.A.; VIVANCO, D.I.; VÁZQUEZ, M. Surimi of fish species from the Gulf of Mexico: evaluation of the setting phenomenon. Food Chemistry, v.75, p.43-48, 2001.

MORRISSEY, M.T.; WU, J.W.; LIN, D.; AN, H. Protease inhibitor effects on torsion measurements and autolisys of pacific whiting surimi. Journal of Food Science, v.58, p.1050-1054, 1993.

MOTOKI, M.; KUMAZAWA, Y. Covalent crosslinking in heated protein systems. Journal of Food Science, v.65, p.221-226, 2000. MURPHY, S.C.; GILROY, D.; KERRY, J.F.; KERRY, J.P. Assessment of added protein/starch on the functional properties on surimi gels manufactured from Atlantic whiting. Journal of Food Science, v.70, p.21-24, 2005.

STATSOFT. Statistica for windows (Computer program manual, Analytical Software). Tulsa, OK, 1998.

TOTOSAUS, A.; MONTEJANO, J.G.; SALAZAR, J.A.; GUERRERO, I. A review of physical and chemical protein-gel induction. International Journal of Food Science and Technology, v.37, p.589-601, 2002.

VISESSANGUAN, W.; AN, H. Effects of proteolysis and mechanism of gel weakening in heat-induced gelation of fish myosin. Journal of Agricultural and Food Chemistry, v.48, p.1024-1032, 2000.

VISESSANGUAN, W.; MENINO, A.; KIM, S.M.; AN, H. Cathepsin L: a predominant heat-activated proteinase in arrowtooth flounder muscle. Journal of Agricultural and Food Chemistry, v.49, p.2633-2640, 2001.

VISESSANGUAN, W.; OGAWA, M.; NAKAI, S.; AN, H. Physicochemical changes and mechanism of heat-induced gelation of arrowtooth flounder myosin. Journal of Agricultural and Food Chemistry, v.48, p.1016-1023, 2000.

YONGSAWATDIGUL, J.; PARK, J.W. Thermal denaturation and aggregation of threadfin bream actomyosin. Food Chemistry, v.83, p.409-416, 2003.

YONGSAWATDIGUL, J.; PARK, J.W.; VIRULHAKUL, P.; VIRATCHAKUL, S. Proteolytic degradation of tropical tilapia surimi. Journal of Food Science, v.65, p.129-133, 2000.

YOO, B.; LEE, C.M. Thermal gelation characteristics of composite surimi sol. Lebensmittel-Wissenschaft und Technologie, v.27, p.533-537, 1994.

$\overline{\text { Recebido em } 27 \text { de junho de } 2008 \text { e aprovado em } 7 \text { de novembro de } 2008}$ 